\title{
Contextualism: Is the act in context the adequate metaphor for scientific psychology?
}

\author{
E. J. CAPALDI and ROBERT W. PROCTOR \\ Purdue University, West Lafayette, Indiana
}

\begin{abstract}
According to some, psychology as it has been practiced is based on a world view known as mechanism. Individuals from a number of different areas of psychology, most recently within the behavior-analytic community, have strongly argued that psychology should be based on a different world view, contextualism. They emphasize a variety of characteristics that, in their view, differentiate a contextualistically based psychology from one based on mechanism. We examine these characteristics and find them to be of dubious value for differentiating a contextualistic approach to psychology from others. One proposal of some advocates of contextualism is that contextualistic approaches should develop independently from most of the remainder of psychology, which they regard as mechanistic. This proposal is said to be derived from the metaphilosophy of Pepper (1942). We evaluate this proposal and reject it. We go on to suggest that the mechanistic/contextualistic dichotomy is too constraining to realistically describe various approaches to psychology.
\end{abstract}

In 1942, Stephen C. Pepper published a book entitled World Hypotheses, in which he presented a framework for classifying philosophic systems. This framework has met with considerable acceptance among a variety of psychologists from different fields over the past two decades. Pepper's classifications have been used by some of these psychologists to reject what may be regarded as the dominant or conventional approaches to theory and research in psychology in favor of certain newer alternatives. If these alternative approaches should come to be widely accepted, the result would be a revolution in the way psychological research is practiced and theory is generated. Any arguments advocating radical change obviously demand close scrutiny. However, although a few of the arguments stemming from Pepper's metaphilosophy have encountered some opposition (e.g., from Kendler, 1986; Marr, 1993; Staddon, 1993), so far they have escaped the extensive examination they deserve. We intend to rectify this shortcoming here.

The most recent proponents of radical change in psychology based on Pepper's metaphilosophy are individuals within the behavior-analytic framework stemming from the work of B. F. Skinner. Because the behavioranalytic arguments, more than others that have been made, are addressed specifically to how experimental psychology is practiced, they are most relevant to members of the Psychonomic Society and deserve particular attention. Although some of the arguments advanced by certain members of the behavior-analytic community are unique, in many cases they correspond to those advanced by other psychologists, such as developmental psychologists. Con-

Correspondence should be addressed to E. J. Capaldi, Psychology Department, Psychology Building 1364, Purdue University, West Lafayette, IN 47967-1364. sequently, by critically focusing on the case advanced by the behavior analysts, we should be able as well to supply a general critique of the more salient arguments offered by various adherents of Pepper's metaphilosophy.

\section{PEPPER'S METAPHILOSOPHY}

According to Pepper (1942), most philosophic positions can be subsumed under one or another of four relatively adequate world views. He goes on to say that each of these world views derives from a distinctive root metaphor that provides a different, coherent, and defensible way of interpreting the world. These four world views are formism, organicism, mechanism, and contextualism.

The root metaphor of the world view known as formism is similarity. The members of any class of objects or ideas are similar to one another either because these members are the reflection of some independently existing norm (Plato) or because we can see in the particulars that all members of the class manifest the norm (Aristotle). For Plato, oak trees are oak trees because they participate in the norm for oak trees, whereas for Aristotle, all oak trees have a common essence. The truth criterion of formism is correspondence of the individual to the characteristics of the class. For example, this particular bird is a bird because it has the characteristics peculiar to the class of birds.

For organicism, the root metaphor is the growing organism. Things are seen as developing toward certain ends, according to predetermined stages. Piaget's stages of cognitive development make up one example of organicism within developmental psychology. The criterion of truth for organicism is coherence. Systems-as, for example, scientific theories-progress over time (i.e., develop) toward greater and greater inclusion or coherence. 
Thus, Newton's theory is superior to that of Anaximenes. Why? "Because, answers the organicist, it includes vastly more data, because these data are much more determinant, and because these determinant data are so closely integrated so that in very large measure they are all mutually implicative"' (Pepper, 1942, p. 300).

Of almost exclusive concern here are the remaining two world views, mechanism and contextualism. According to Pepper (1942), the root metaphor of mechanism is the machine. The parts of the machine are assumed to interact in a lawful manner to produce the functioning of the entire machine. For example, the earth revolves around the sun in a fixed pattern determined by the mutual gravitational attraction of the two bodies. Mechanism is regarded by many as the metaphor of science and of most contemporary psychology (e.g., Gillespie, 1992; Morris, 1988). Mechanism would be identified with Newton's approach, for example. Newton attempted to explain a variety of phenomena on the basis of a small set of laws. The truth criterion of mechanism is correspondence between hypothesis and experimental findings. This version of the correspondence criterion of truth is so well known and widely accepted as to require no elaboration.

The root metaphor of contextualism is the ongoing act in context. Contextualism stems from pragmatism and is associated with the philosophic systems of William James, C. S. Peirce, and John Dewey. In contextualism, things are always seen as changing, but the change is not necessarily progressive, as in organicism. According to Pepper (1942), "The ineradicable contextualistic categories may thus be said to be change and novelty" (p. 235). Pepper states, "To give instances of this root metaphor in our language with the minimum risk of misunderstanding, we should use only verbs. It is doing, and enduring, and enjoying" (p. 232). Contextualism favors an operational theory of truth, which has three distinct specifications. One of these truth criteria is that of "successful working." In terms of this criterion, Pepper states, "Truth is utility or successful functioning, and that is the end of it" (p. 270). According to Pepper, the successful working criterion eschews hypothesis testing altogether. The true is whatever works in a particular situation. For example, a rat finding its way to the goalbox has solved a practical problem and, thus, has isolated the true path. Because it will be more appropriate to consider the other two truth criteria later in this paper, we defer consideration of them.

\section{THE EMERGENCE OF CONTEXTUALISM IN PSYCHOLOGY}

Since about 1970 , the notion that mechanism is the proper world view for science in general and psychology in particular has come to be increasingly rejected. It has been argued by a diverse array of psychologists that contextualism provides either an additional approach to psychology or one that should replace mechanism entirely (Ford \& Lerner, 1992; Hayes, Hayes, Reese, \& Sarbin, 1993: Rosnow \& Georgoudi, 1986). For example, Morris
(1991), a behavior analyst, has argued that "for psychology, mechanism is the wrong world-view for its subject matter, and always was" (p. 124). He goes on to say, "Contextualism, though, is the bold new alternative-an alternative that is continuing to evolve" (p. 143).

Contextualism has had its initial and major impact on developmental psychology (see, e.g., Ford \& Lerner, 1992; Lerner \& Kaufman, 1985; Reese, 1991). It also has been influential in environmental psychology (e.g., Altman \& Rogoff, 1987), social psychology (e.g., Gergen, 1989), and clinical psychology (e.g., Terwee, 1990). A recent book by Gillespie (1992) argues that cognitive psychology should become contextualistic, and contextualism has been strongly advocated as the proper approach for behavior analysis in particular and for psychology in general (e.g., Hayes, Hayes, \& Reese, 1988). Despite the numerous differences among the advocates of contextualism, a theme that runs through the various contextualistic accounts is that stimulus-response (S-R) psychology and cognitive psychology are highly similar, in that both are exemplars of mechanistic systems and have serious shortcomings as approaches to psychology.

One may judge the fervor with which some have come to embrace contextualism from remarks by Sarbin (1993), a personality-social psychologist. He states that coming to accept contextualism in place of mechanism is a very difficult experience, requiring "something akin to religious conversion"' (p. 53). To begin to appreciate how different his contextualistic approach is from the so-called mechanistic approach, consider the following:

We have crossed the threshold into a new era. We have joined ranks with scholars who make the case for social constructivism, for hermeneutics, for ethnomethodology, for psychobiography, for dramaturgy, for narrative psychology, for ethogeny, all patently contextual, all ready to advance knowledge through the study of exemplars or specimens. We have lived through a conversion experience, and can now see the world from the perspective of contextualism, the root metaphor of which is the narrative. We live in a story shaped world. Looking back, the dream of a productive and complete science of psychology based on mechanistic principles served as a powerful incentive to do psychology according to the conventional paradigm. Today, we acknowledge that it was only a dream. (p. 63)

\section{THE CASE FOR CONTEXTUALISM ADVANCED BY BEHAVIOR ANALYSTS}

Among the most ardent advocates of contextualism in the past few years have been several behavior analysts. Behavior analysis, in common with much of the remainder of psychology, has in the past been considered by some to be based on the world view known as mechanism (see, e.g., Gillespie, 1992; Morris, 1988, 1993a). Many behavior analysts continue to see psychology in general, but not behavior analysis, as mechanistic (Hayes, 1988; Hayes et al., 1988; Morris, 1988). Hayes et al. state flatly, "Behavior analysis is a contextualistic system" (p. 110). Similarly, Morris (1988) asserts that "contemporary behavior analysis ... is contextualistic in world view, in contrast 
to its traditional characterization as being mechanistic" (p. 289), and Hineline (1990) states, "in its purest form, behavior analytic theory is contextualistic to the extent of virtually excluding mechanistic metaphors"' (p. 309).

The initial and most influential arguments for behavior analysis' being contextualistic rather than mechanistic were advanced in a review of Pepper's (1942) book by Hayes et al. (1988), which appeared in the Journal of the Experimental Analysis of Behavior. Some of the arguments made by Hayes et al. are unique to behavior analysis; others overlap with those made by psychologists in other areas. According to Hayes et al. (1988), the contextualistic features of behavior analysis that distinguish it from mechanism are the concept of the operant, the criterion for truth or adequacy, the role of the scientist in scientific analysis, and the possibility of novelty. Additional arguments suggesting that behavior analysis is contextualistic have subsequently been supplied by Morris (1988, 1991, 1993a, 1993b). The arguments advanced by Morris, who sees considerable similarity between behavior analysis and developmental psychology, provide additional correspondence to those advanced by contextualists in other areas of psychology. Morris suggests that contextualistic behavior analysis, unlike mechanistic approaches found in S-R psychology and cognitive psychology, is holistic rather then elementaristic, postulates an active rather than a passive organism, rejects linear causality, and is not reductionistic.

It is one thing to describe contextualism and mechanism as abstract systems, as Pepper (1942) has done. But it is another thing to suggest what the implications of the two positions might be for concrete scientific practice, as many psychologists have done. It is of course the latter activity that is of concern here. We will suggest that many of the characteristics said to render behavior analysis, or indeed any other area of psychology, a contextualistic system fall into one of two categories: Either they are for one reason or another of dubious value for that purpose, or, as occurs in the majority of cases, they can be found in equal abundance in most approaches to psychology. If we are correct, then either all of psychology is contextualistic or, as we think, the criteria are vacuous.

Notice that, according to the position advanced here, we are not arguing that psychology or some area of psychology is or is not contextualistic, or mechanistic for that matter. Rather, our purpose consists in demonstrating that a convincing case has not been made that behavior analysis in particular or scientific psychology in general, as currently practiced, is or has been contextualistic. Perhaps convincing arguments can be advanced, but so far, we shall argue, this has not been the case. Having reached this conclusion, we will go on to examine and reject a view advocated by Hayes et al. (1988) that contextually minded psychologists should not compete directly with mechanistically minded psychologists. Finally, we will raise a neglected question: How appropriate is it to apply the terms contextualism and mechanism to science in general and to psychology in particular?

\section{THE ARGUMENTS FOR CONTEXTUALISM: A DETAILED EXAMINATION}

The previously mentioned arguments advanced by Hayes et al. (1988) and by Morris (1988, 1991, 1993a, 1993b) for classifying a given psychological approach as contextualistic will be examined below. In considering whether an approach is contextualistic, neither Hayes et al. nor Morris, nor any other adherent, has suggested that a specific combination of characteristics must be taken together. Rather, they have merely listed in serial fashion the characteristics that, in their opinion, render a particular approach contextualistic. Therefore, in this paper, we evaluate each of these purported characteristics in serial fashion.

\section{Contextual Characteristics of the Operant}

According to Hayes et al. (1988), contained in contextualism is a view of behavior that is compatible with the concept of the operant, as it has been developed in behavior analysis. Therefore, the operant has several major characteristics that Hayes et al. see as particularly compatible with contextualism. However, as discussed below, each of the purported contextualistic characteristics of the operant identified by Hayes et al. can be found in other psychological approaches that have not been considered contextualistic.

Act in context. In contextualism, the context must be included in the analysis of an act, because an act out of context is not an act, and this is true of the operant, according to Hayes et al. (1988). They state, "The events participating in an operant cannot usefully be examined independently because their nature depends on their relations to the other participants" (p. 101). We suggest that although it may be true that behavior analysts include context in the analysis of the act, the importance of including context is similarly recognized in many branches of psychology, if not by all psychologists. However, recognizing that context may be of critical importance in many instances does not make one a contextualist in the sense discussed in this article.

The importance of context has been recognized in a recent book on learning, entitled Context and Learning (Balsam \& Tomie, 1985), of which the following are among a small sample of the opinions expressed by chapter authors. Balsam states, "At a logical and procedural level, all learning occurs in context" (p. 1). Similarly, Rescorla, Durlach, and Grau (1985) state, "Modern discussions of Pavlovian conditioning increasingly acknowledge the importance of the context in which learning and performance occur"' (p. 23). Also, Medin and Reynolds (1985) state,

The present chapter describes work where context is afforded a central status and where context effects are manifest as strengths as well as limitations. We aim to show that analyses of context can provide insights into some key problems associated with learning and memory research. (p. 323) 
Clearly, the authors of these chapters, in common with other authors in the book, acknowledge the importance of context for understanding learning. An extended discussion of how a variety of modern learning theories deal with context may be found in Hall (1991).

The inclusion of context is hardly limited to learning theories. Context is also presumed to play a crucial role in perception, cognition, and memory. Jenkins, a theorist widely recognized as emphasizing context in his approach to memory, goes so far as to say this of modern memory theory: "Everyone now knows that memory phenomena are much more complicated and contextually determined than we used to think they were" $(1979$, p. 430 , emphasis ours). The importance attributed to context in memory research is illustrated by the wide variety of studies examining environmental, internal, and semantic context, many of which are reviewed in the book Memory in Context: Context in Memory (Davies \& Thomson, 1988).

Consider now perception. One of the classic studies in this area is an experiment by Bruner and Minturn (1955), in which an ambiguous character was read as a letter when presented along with letters and as a number when presented along with numbers. In other words, the perception of the stimulus was influenced by the context in which it was embedded. Another example is the phonemic restoration effect discovered by Warren (1970). He presented subjects with sentences such as the following, in which the asterisk indicates a phoneme replaced by a nonspeech sound:

It was found that the *eel was on the axle.

It was found that the *eel was on the shoe.

It was found that the *eel was on the orange.

It was found that the *eel was on the table.

Even though the disambiguating context occurred after the missing phoneme, subjects reported actually hearing for each of the four sentences above wheel, heel, peel, and meal, respectively. Many other examples from other areas of psychology could be cited.

Although indicating that mechanists deal with context, Hayes (1988) and Morris (1991) suggest that they do so differently from contextualists. For example, Hayes (1988) states, "For a mechanist, context is relevant, but it does not alter the nature of the act itself"' (p. 11). Similarly, Morris suggests that in contextualism, unlike in mechanism, "context imbues behaviour with meaning; the meaning of behaviour emerges from its context" (p. 136). We think that the view expressed by Hayes and Morris is only partially correct. In some instances, the possibility that context is simply another variable influencing behavior, albeit an important one, is justified. Baddeley (1982) has used the term independent context to refer to such instances. In other instances, however, context does have more fundamental effects; but this is generally realized and accepted by all researchers. In these instances, which Baddeley has called interactive context, the meaning of behavior is determined by the context in which it occurs. For example, fire uttered in a theater has an entirely different meaning than fire uttered on the rifle range. Moreover, the phonemic restoration effect described above illustrates that context can alter the act of hearing itself.

A good example of a theory in which context is fundamental to determining what is learned is supplied by Gibbon and Balsam's (1981) scalar expectancy theory (SET). Gibbon and Balsam state, "The central idea espoused is that the association between the signal and food depends on an appreciation of the improvement in the average delay to reinforcement in the signal compared with the average delay overall or in the background" (p. 248). According to SET, to judge the effect of a particular learning trial, we have to take into account not only that learning trial but its relation to other events. More specifically, strength of expectancy in the signal and strength of expectancy in the background are constantly undergoing change, both in absolute terms and relative to each other, depending on (1) whether the reinforcing event follows the signal, and at what delay or trace interval, (2) whether the signal occurs alone, (3) whether the reinforcing event occurs alone, and (4) the temporal spacing of events in the background, including no event in the background. Just as Hayes et al. (1988) say that the events participating in an operant cannot usefully be examined independently, Gibbon and Balsam are saying that the effect of a Pavlovian trial cannot be judged independently of its relationship to (1), (2), (3), and (4) above.

Outside the act. Contextualists analyzing an act find themselves outside of the original event of interest, and so too do behavior analysts, according to Hayes et al. (1988). We suggest that while this may be true, it is also the case that mechanists analyzing events often find themselves outside of the original event of interest. For example, in an attempt to understand the effects of context on, for example, learning or perception, so-called mechanistically oriented psychologists attempt to construct theories. In this way, they find themselves outside of the original event of interest. Thus, a theory developed in an attempt to understand the effects of context on a particular behavior may be applied to a variety of other different behaviors (see, e.g., Hall, 1991). It is the attempt to understand context, and not whether one is either a mechanist or a contextualist, that results in one's interest's being directed outside of the original act. This may be illustrated by the recently reported finding that preexposure of the conditioned stimulus (CS) affected sensitivity to context (Swartzentruber \& Bouton, 1992). Three distinct explanatory mechanisms were suggested-that preexposure of the CS might affect its associability, its processing, or retrieval of the CS-US association. Each of these distinct explanations suggests a different line of further investigation outside of the original event of interest.

Acts versus movements. Responses share membership in an operant class to the extent that they produce common effects on the environment, according to Hayes et al. 
(1988). They go on to say that an operant may be anything from a thumb twitch to cooking a four-course meal. Morris (1991) makes the same argument, in a somewhat different manner. He states, "Mechanism adheres to elementarism, representing behavior and the environment as but collections of materially fundamental, atomic responses and stimulus elements (or switches). Complex action is then but an associative compounding of the basic elements and their interrelations"' (p. 132).

Although some psychologists may identify the animal as learning particular and specific behaviors, the idea that responses share membership in an operant class to the extent that they produce common effects on the environment has long been recognized by many psychologists. Indeed, it was examined experimentally by Muenzinger (1928) prior to the time it was emphasized by behavior analysts. The well-known Muenzinger study was prominently mentioned by Tolman (1932), a cognitive behaviorist, to illustrate the "multiple trackness" of behavior. In that study, guinea pigs given over 1,000 acquisition trials used a variety of responses over the course of the experiment. Thus, the animal might use its left paw for a number of trials and then switch over to using its right paw, and then switch again to using its left paw.

Tolman (1932) cites another study by Muenzinger, Koerner, and Irey (1929), in which the experimenters limited the animals to the use of the right paw. However, even here, the animals showed considerable response variability. In Muenzinger et al.'s words:

\begin{abstract}
The right paw might be used with a firm and deliberate pressing down of the lever, or a bare touch on the lever, or a quick tap, or a succession of quick taps, or brushing or sliding over the lever, or circular movement partly around the lever, or a gentle placing of the paw on the lever with pressure after some time, or a crossing of the right paw over the left. (p. 427)
\end{abstract}

All of these behaviors were regarded by Tolman and Muenzinger as equivalent, despite their physical differences.

Tolman's approach emphasizing response equivalence continues to be influential on the contemporary scene. For example, Mackintosh (1974) specifies several theories of instrumental learning that "may be regarded as modern versions of the theory of learning advanced by Tolman (1932)" (p. 199). Mackintosh continues, "One of the most direct sources of support for such a theory is that provided by evidence of response equivalence"' (p. 199). Mackintosh then goes on to cite many additional experimental examples of the sort of findings originally reported by Muenzinger and colleagues.

The view that behavior may be characterized in terms of acts rather than specific movements has been so widely accepted that we find the contrary opinion expressed by Hayes et al. (1988) and Morris (1991) to be utterly without foundation. For example, Spence (1956), a leading S-R psychologist, said, "Certainly all of the responses involved in instrumental conditioning and selective learning situations would be classified as acts rather than movements, and contrary to common belief, even the responses employed in classical conditioning appear to fall in this category" (pp. 42-43). Moreover, Adams (1984), an expert in the area of motor learning, has suggested that although concern with the act is legitimate, so is concern with movement sequences. He has gone so far as to state that preoccupation with the act in both human and animal learning has had deleterious consequences for the understanding of movement sequences (see especially pp. 3 and 4 of his article).

Verbs. In contextualism, the verb-like quality of behavioral interaction is emphasized. This is true of behavior analysis, according to Hayes et al. (1988), as well as Morris (1993a), who states, "Behavior analysis takes as its subject matter what we describe in the grammar of verbs-behaving, constructing, and thinking"' (p. 28). Compare Morris's statement to that of Tolman (1932):

A rat running a maze; a cat getting out of a puzzle box; a man driving home to dinner; a child hiding from a stranger; a woman doing her washing or gossiping over the telephone; a pupil marking a mental-test sheet; a psychologist reciting a list of nonsense syllables; my friend and I telling one another our thoughts and feelings - these are all behaviors. (p. 8)

As may be seen, even for a cognitive behaviorist presumably on the opposite pole from behavior analysis, the operant need not be restricted to any particular class of behavior, and each of the behaviors described by Tolman emphasizes verb-like interactions, no less than those described by Morris above. Would it be possible for any variety of behaviorism to ignore the verb-like quality of behavioral interactions?

It seems clear to us that a point-by-point comparison of the contextualistic position adopted by Hayes et al. (1988) on the operant with that of Tolman (1932) and subsequent writers on the nature of the response would reveal them to be highly similar, to the point of being almost identical. Perhaps this is not accidental. In his later writings, Pepper (1967) favored a new world view, seen by him as highly similar to contextualism, called selectivism. Selectivism was heavily influenced by the writings of Tolman. The root metaphor of this new world view is the goal-seeking, purposive act, which Pepper saw as an adaptation of the position advocated by Tolman in his 1932 book, Purposive Behavior in Animals and Men. It may be that in focusing on acts in context, one is driven to an analysis of behavior that stresses goals and purposes, as exemplified by Hayes and Hayes's (1992) treatment of the goals of analysis. Thus, many implications that follow from contextualism, such as stressing goals and purposes, for example, may follow equally well from other positions that would not typically be considered contextualistic.

\section{The Role of the Scientist in Scientific Analysis}

There are two features of the contextualistic approach to science that Hayes et al. (1988) suggest differ from those of a mechanistic approach. First, contextualists "believe that scientists cannot stand apart from the world under analysis; they are, rather, a part of that world" 
(p. 103). Second, contextualists suggest that science is not directed "toward the attainment of ultimate knowledge" (p. 103). Although these positions may characterize the views of contextualists, they also would be widely accepted by psychologists and scientists of various persuasions, and we cannot understand how this could be doubted.

Hanson (1988), a philosopher of science who is quoted favorably by a wide variety of psychologists, suggests that our very observations are influenced by the theories that we hold. He states:

To say that Tycho and Kepler, Simplicius and Galileo, Hooke and Newton, Priestley and Lavoisier, Soddy and Einstein, De Broglie and Born, Heisenberg and Bohm all make the same observations but use them differently is too easy. It does not explain controversy in research science. Were there no sense in which they were different observations, they could not be used differently. (p. 193)

It is hard to imagine a more intimate relationship between scientists and their subject matter than that suggested by Hanson, because it involves perception itself. Most books on psychological research methods state flatly that our observations are influenced by our preconceptions. Indeed, in an undergraduate research methods book, Meyers and Grossen (1978) cite Hanson favorably in making this point.

Few, if any, psychologists would claim that science deals with ultimate knowledge. Consider a point of view suggested by Evans (1985) in a textbook on research methods:

Reflecting the skeptical attitude, scientific understanding is tentative and ever-changing. Thus, theories and conclusions are constantly undergoing revision as additional data are accumulated. The replacement of Newtonian physics with relativity theory and quantum mechanics is a classic example of this. In Newton's day, his view of the universe was the truth. But the truth changed rather quickly with the appearance of new accounts that could explain more. (p. 19)

The examples above were obtained simply by examining a few books at random. Dozens of similar examples could be found with relatively little effort. If this be doubted, consider Kuhn (1970), certainly one of the most influential philosophers of science on contemporary psychology. As regards standing apart from one's subject matter, Kuhn (1970) suggests, "To an extent unparalleled in most other fields, they [the members of a scientific community] have undergone similar educations and professional initiations; in the process they have absorbed the same technical literature and drawn many of the same lessons from it"' (p. 177). As a result of these educational experiences, members of a scientific community are constrained to see matters in a particular way and find it difficult to communicate with others educated in a different "disciplinary matrix."' As for ultimate truth, Kuhn states:

I do not doubt, for example, that Newton's mechanics improved on Aristotle's and that Einstein's improved on Newton's as instruments for puzzle-solving. But I can see in their succession no coherent direction of ontological de- velopment. On the contrary, in some important respects, though by no means all, Einstein's general theory of relativity is closer to Aristotle's than either of them is to Newton's. (pp. 206-207)

To summarize, there seems to be little doubt that psychologists in general, in common with contextualists, believe that scientists do not stand apart from their subject matter and that ultimate knowledge is not within our grasp.

\section{The Possibility of Novelty}

Regarding the contextualistic category of novelty, Hayes et al. (1988) note that "this aspect of contextualism does not have obvious parallels in behavior analysis" (p. 103). However, they go on to assert that "the contextualistic concept of novelty does indeed show up in behavior analysis"' (p. 103). One problem with this view is that novelty is not defined in a clear, unambiguous manner by either Pepper (1942) or Hayes et al. That is, no contextualist, to our knowledge, has indicated how we would recognize novelty when and if it should occur. For example, how would we distinguish between an event unexpected on the basis of current scientific theory and one that was truly novel? Failure to deal with this issue is a very serious deficiency, for we lack the criteria for evaluating a fundamental category of contextualismnovelty. Another problem with novelty, as specified by pure contextualism, is that it does not preclude total disorder. As Cicirelli (1994) has suggested, "In pure contextualism, not only is there no end-point to development, but the direction of development is totally unpredictable" (p. 34).

These problems aside, one possible meaning of novelty is that laws or phenomena that hold for one period, however long or short, may not hold in some succeeding period. Clearly, being a contextualist is not a necessary requirement for acknowledging this logical possibility. It is one that seems as open to mechanists, formists, and organicists as to contextualists. None of us is in a position either to affirm or deny that laws are or are not immutable. In any event, whether or not the possibility of novelty in this sense is accepted would seem to have no impact on how science is practiced, unless or until such novelty appears and, moreover, is recognized.

\section{Active Versus Passive Organism}

Morris (1991) states, "Within the mechanistic account, causation is characterized in terms of the effects of efficient independent causes on dependent material-material that is otherwise at rest'" (p. 134). Morris suggests that in contextualism, as opposed to mechanism, performance must be understood in terms of an environment interacting with the organism. The notion that a passive organism is postulated by all but contextualists is simply incorrect. That the organism is an active information processor has been advocated in any number of sources, a few of which we will cite here.

In a classic paper, which deals with the problem of serial order behavior, whose influence in a variety of areas of 
psychology would be difficult to overestimate (see, e.g., Bruce, 1994), Lashley (1951) indicated:

\begin{abstract}
My principal thesis today will be that input is never into a quiescent or static system, but always into a system which is already excited and organized. In the intact organism, behavior is the result of interaction of this background of excitation with input from any designated stimulus. Only when we can state the general characteristics of this background of excitation, can we understand the effects of a given input. (p. 112)
\end{abstract}

Similarly, Postman (1972), in characterizing the organizational approach to memory, said the following:

One of the sources of appeal of the concept of organization is undoubtedly that it implies an active learner who imposes structure on the material to which he is exposed. The subject is credited with discovering and utilizing the systematic features introduced into the material by the experimenter, and also with inventing idiosyncratic bases of organization. (p. 18)

In a widely used textbook concerned with human memory, Klatzky (1980) described her approach as follows: "From the information-processing perspective adopted by this book, ... human memory is depicted as a continuously active system that receives, modifies, stores, retrieves, and acts upon information"' (p. ix). More recently, in a textbook devoted to animal and human memory, Spear and Riccio (1994) state that there has been an "increasing realization that humans typically are active rather than passive processors of the information to be learned" (p. 13). Thus, from at least the early 1950s to the present, it has continuously been recognized that learners are active rather than passive in the processing of information.

\section{Linear Causality}

Another characteristic that Morris (1993a) attributes to mechanism and that has been accepted by contextualists in general is unidirectional, linear causality. Morris says, "In adhering to unidirectional and linear causality, the mechanists explanatory model is an asymmetric, one-way relation between independently defined causes and effects" (p. 34). Morris means by this that organisms are merely the recipients of the forces that act upon them. The arch-mechanist, Newton, would hardly agree with this. Newton's third law of motion states as follows: To every action there is always opposed an equal reaction; or, the mutual actions of two bodies upon each other are always equal and directed toward contrary parts (Halliday \& Resnick, 1966).

How can such a serious misunderstanding of mechanism be explained? The likely reason has to do with the way that experimental research is normally conducted. In experimental arrangements, as a practical matter, scientists seek to examine the effects of independent variables on dependent variables. They are well aware, however, that effects occur in the reverse direction, but ignore them not for epistemological or ontological reasons but for purely practical ones. If our reasoning here is correct, contextualists have attributed to scientists beliefs they do not hold, mistaking strategic features for ontological ones.

\section{Reductionism}

Morris (1993a) argues that, unlike contextualism, mechanism, and thus psychology in general, is necessarily reductionistic in the sense that the aim is to reduce psychology to a more fundamental discipline, ultimately physics. We find this viewpoint to be fallacious for two reasons. First, as Bechtel (1988) has indicated, within psychology in general and cognitive psychology in particular, there is a considerable difference of opinion as to whether reductionism, in Morris's sense, is possible. Fodor (1974), for example, is an outspoken opponent of reductionism within cognitive psychology, contending that it is not possible to construct bridge laws equating terms in psychology with those of lower-level disciplines.

A second matter that Morris's view overlooks is that, even within mechanism, a major alternative approach to reductionism, interfield theory, has been proposed. Interfield theory is regarded by some as more realistic than reductionism. Bechtel indicates that interfield theories "do not attempt to derive one theory from another but rather seek to identify relationships between phenomena studied by the two different fields of inquiry" (p. 97). After describing a variety of mechanistic examples of interfield theory, Bechtel goes on to state the following:

The mechanistic interfield theories sketched here open another possibility. This model can accommodate interaction between cognitive and neural inquiries without requiring reduction. It allows both analyses to inform each other in the attempt to develop an interfield theory, but does not require subsuming one explanation under another. (p. 107)

\section{The Criterion for Truth}

Both Hayes et al. (1988) and Morris (1988) argue that the truth criterion for contextualism is different from that espoused by mechanism and corresponds to that already employed by behavior analysis. This criterion is that of successful working, which "implies success with regard to the accomplishment of some potentially attainable goal" (Hayes et al., 1988, p. 102). In another paper, Hayes (1988) states, "all events and all analyses are evaluated in terms of successful working" (p. 12). Hayes also says, "More than anything else it is this truth criterion that shows the contextualistic qualities of behavior analysis" (p. 11). There is a major problem with this argument, in our view.

According to Pepper (1942), successful working is not the best truth criterion of contextualism (p. 272). How the contextualistically minded behavior analysts have managed to ignore Pepper's position on this issue is difficult to understand, because Pepper states it so clearly and explicitly:

The "successful working"' theory excludes hypotheses from truth, yet hypotheses are prominent textures in contextualism, and they are the very textures to which usage im- 
plies truth and falsity. A contextualistic theory of truth that leaves hypotheses out of the theory is not fitting commonsense truth as closely as possible into the contextualistic categories. In fact, the "successful working" theory is only a halfhearted contextualistic theory. (p. 272, emphasis ours)

Pepper goes so far as to say that successful working is not only the narrowest of the truth criteria of pragmatism, but also "the one the enemies of pragmatism try to associate with it" (p. 269). On the basis of our reading of the philosophical literature on pragmatism, we would certainly agree with Pepper's evaluation of successful working and think that most pragmatists would too. It is beyond our understanding why modern proponents of contextualism in psychology would associate themselves with a position that in the past has been used to undermine their cause.

Pepper (1942) describes two other more adequate contextualistic truth criteria. The first of these is that of verification of hypotheses. "The slogan of this type of operationalism is that truth is verification. According to this formulation, it is not the successful act that is true, but the hypothesis that leads to the successful act"' (p. 272). The trial-and-error behavior of a rat in a maze would produce true and false judgments according to the successful working criterion, but not according to the verified hypothesis criterion. However, if the animal were entertaining some hypothesis as to the correct path, its judgments would be true or false. The verification criterion seems more in character with the rest of psychology than with behavior analysis.

A third truth criterion is qualitative confirmation, which, like the second one, emphasizes confirmation of hypotheses. However, it adds to this the view that "the body of hypotheses possessed by science and philosophy gives us a considerable amount of insight into the structure of nature"' (Pepper, 1942, p. 278). Pepper does not elaborate on what he means by the structure of nature. In any event, the two more adequate truth criteria of contextualism, as described by Pepper, are quite close to the general position adopted by most psychologists. Consequently, the truth criterion of successful working cannot be used to suggest that some area of psychology is more contextualistic than the remainder of psychology.

\section{HAYES ET AL.'S INTERPRETATION OF THE RELATIONSHIP BETWEEN MECHANISTIC AND CONTEXTUALISTIC SYSTEMS}

According to Hayes et al. (1988), who claim to be expressing Pepper's belief, with which they agree, different world views "cannot compete directly" (p. 98). Moreover, as regards conflicts between world views, Hayes et al. (1988) state, "According to Pepper, world views are orthogonal to each other and therefore cannot conflict. Apparent conflicts are really pseudoconflicts. ... These kinds of conflicts are illegitimate and cannot be resolved; they can only be recognized" (Hayes et al., 1988 , p. 105). World views, they maintain, must and should develop in isolation from each other. Must, because effective communication between different world views is impossible. And should, because conceptual confusion arises from mixing of metaphors.

Hayes et al. (1988) state, "using the categories of one world view to analyze and criticize another is illegitimate and inherently useless" (p. 98). In another place, Hayes (1988) says, "Pepper claimed that it is illegitimate to criticize one world view in terms of the categorical concepts of another" (p. 12). That, in Hayes's opinion, there is little to be gained from either competing with or criticizing mechanistic positions, or attending to their criticisms, is clear from the following statement: "The only true intellectual allies and adversaries of a given specific position will always be found within a given world view" (Hayes, 1988, p. 13). Hayes and Hayes (1992) state in connection with mechanistic and contextualistic versions of radical behaviorism, "The two positions are incompatible, and the differences cannot be resolved by way of a compromise" (p. 231). The astounding implication of this position, it will be recognized, is that contextualistic behavior analysis should be as independent of mechanistic behavior analysis as of most of the remainder of psychology.

The first weakness of the preceding argument is, as we have shown previously, that the criteria which are said to distinguish between contextualistic and mechanistic approaches to psychology fail to do so. A second weakness, in our opinion, is that the contextualistically minded behavior analysts have misinterpreted Pepper's (1942) position on the competition between world views, although we must admit that Pepper is to some extent ambiguous on this score. Consider the following statements from Pepper:

It is illegitimate to disparage the factual interpretations of one world hypothesis in terms of the categories of another-if both hypotheses are equally adequate. (p. 98)

It is the cognitive obligation of a world theory to interpret the danda [a type of corroboration] and categories of other world theories in terms of its own categories. (p. 100)

We need all world hypotheses, so far as they are adequate, for mutual comparison and correction of interpretive bias. (p. 101)

When we say that world theories are mutually exclusive, we do not mean that they stand apart from one another like so many isolated posts. Each theory is well aware of the others, criticizes and interprets them, and entirely includes them within its scope. (p. 104)

Pepper's (1942) entire treatment of this issue seems to suggest that the world views are in a constant state of growth and healthy competition. How can our interpretation of Pepper on the relation between world views be reconciled with that of Hayes et al. (1988)? In our view, Pepper discouraged criticizing the fundamental assumptions of one world view in terms of the fundamental assumptions of another world view, much as one might criticize an ethical system from a scientific viewpoint. Clearly, criticism of this sort is not particularly useful. Pepper did 
not intend, however, to discourage criticizing what we shall call the products of a particular world view from some other standpoint. Examples of products include such things as some particular theoretical formulation that is developed from within a world view (e.g., Hull's mechanistic S-R theory) or some particular methodology that stems from a world view (e.g., factor analysis or statistics, generally). Our interpretation of Pepper is that such products of world views are fair game for competition, conflict, and criticism. (See Gillespie, 1992, for a contextualist who agrees with our view on competition between contextualistic and mechanistic systems.) In our opinion, then, Pepper encouraged, rather than discouraged, meaningful dialogue between individuals who subscribe to different world views concerning the products of those views.

Regardless of whether our interpretation of Pepper or that of Hayes et al. (1988) is the correct one, we would suggest a third reason for rejecting their position that contextualistic systems should develop in isolation from other formulations, such as mechanistic behavior analysis and cognitive psychology: It is a course of action that seems counterproductive. By not engaging in dialogue with others over specific interpretive and methodological differences, one invites the charge of being unreasonable, if not anti-intellectual. No scientific approach that is seen as being either unreasonable or anti-intellectual will be able to exercise influence beyond its own boundaries. This surely is not an end to be desired, even if further, more adequate arguments than have been supplied so far should ultimately reveal some portions of psychology to be contextualistic.

We recognize that it is always difficult for people of different persuasions to communicate with each other, but we do not see this problem as an insurmountable one. On the problem inherent in such communication, we agree with the prominent philosopher of science, Karl Popper (1970), who has commented as follows:

I do admit that at any moment we are prisoners caught in the framework of our theories; our expectations; our past experiences; our language. But we are prisoners in a Pickwickian sense; if we try, we can break out of our framework at any time. Admittedly, we shall find ourselves again in a framework, but it will be a better and roomier one; and we can at any moment break out of it again. The central point is that a critical discussion and a comparison of the various frameworks is always possible.... The difficulty of discussion between people brought up in different frameworks is to be admitted. But nothing is more fruitful than such a discussion. (pp. 56-57)

\section{HOW APPROPRIATE IS IT TO APPLY THE TERMS CONTEXTUALISM AND MECHANISM TO PSYCHOLOGY?}

Having examined a number of articles and books written by contextualistically minded psychologists, we find no contextualist who has quarreled with Pepper's (1942) division of all philosophic systems into formism, organicism, mechanism, and contextualism. Such seemingly uncritical acceptance does not seem entirely healthy to us. Consider, for example, the proposition that the commonly accepted metaphor for science in general and psychology in particular is the machine. We have two observations about this proposition. First, even if one accepts the machine metaphor, and certainly it has been used extensively within some areas of psychology, it does not imply that one literally thinks that all aspects of psychology are machine-like. Take the metaphorical utterance, The President is the captain of the ship of state. We do not literally think that the President is steering a ship. Rather, what we attempt to illuminate by this metaphor is that in forming government policy the President must avoid making mistakes (i.e., avoid the reefs), that he must generate the best possible plan (steer a good course), that the final decision is his (as a captain is in charge of the ship), and so on. In other words, when using metaphors, we take them not literally but metaphorically. As du Preez (1991) has indicated,

What we ought to do is to attempt to explore the range and power of each metaphor as a heuristic device. Each opens up a set of problems, questions and possible answers. Each can be no more than a slice of the total. (p. 26)

Our second point is that, as the preceding quote implies, the machine metaphor is not the only popular metaphor within psychology. For example, du Preez (1991) suggests that the foundation metaphor for social psychology is theater (roles, actors, role distance, role relations, scripts). Another popular metaphor in many areas of psychology is games. As other examples, the mind has been considered to be a blank slate to be written on by experience (Locke) or an active organizing space with a priori ideas and theories (Chomsky). Many other metaphors that are commonly used in psychology could be added to this list (see du Preez, 1991).

Thus, characterizing science exclusively in terms of the machine metaphor has serious limitations. There is a better way to characterize science, in our opinion. We prefer to think of science as an empirical, analytic endeavor that deals with closed as well as open systems. By a closed system, we mean one in which the ideal is to exclude from consideration all variables except those that we wish to examine. A prime example of a closed system is what scientists attempt to achieve in conducting experiments. Note that the empirical/analytic approach is useful no matter what the metaphor employed to characterize psychology - a machine, a stage, a game, etc.

By an open system, we mean one in which significant variables not under the control of the investigator intrude to influence the phenomena of interest. Open systems are to be found when one examines behavior in real world settings. One example of an open system is what contextualists mean by the term multilevel context. In a multilevel context, behavior would be understood in terms of "atomic, molecular, chemical, biological, physical, psychological, community, social, societal, cultural, and 
historical variables, and so on"' (Cicirelli, 1994, p. 32). For many contextualists, examining phenomena in closed systems distorts the phenomena or limits their generality to restricted if not artificial contexts.

Gillespie (1992), an advocate of a contextualistic approach to cognitive psychology, utilizes a multilevel analysis in her attempt to decide whether or not to send her daughter, Gemma, to kindergarten. Gillespie concludes that a better decision could be made by employing multilevel contextualistic categories rather than those normally associated with closed systems. She may be correct in this judgment. However, the problem of whether or not to send Gemma to kindergarten is not one that admits of a scientific answer. It is doubtful that we have general laws that apply to this particular case. Even if we had such laws, we could not apply them to Gemma because we know little of her social, cultural, and genetic background, to which these laws would presumably apply. We also lack knowledge of the kinds of situations that Gemma might encounter in kindergarten. Is the teacher there to her liking? Will her classmates be friendly or unfriendly? The failure to have answers to these and many other questions precludes a scientific analysis of this and like examples of open systems.

It may be that in some open, multilevel systems, an interpretive (i.e., hermeneutical) approach is more useful than one based on information from closed systems. As one example, a contextualistic-interpretive analysis might provide a better basis for action than an empirical/analytic one in the case of Gemma. As another example, a hermeneutical approach to an open system might provide interesting hypotheses (context of discovery) that could then be subjected to empirical analysis in a closed system (context of justification). No doubt much useful science has been produced in just this way. Be this as it may, we see the distinction between open systems (in which interpretation may be practiced) and closed systems (in which variables may be isolated) as much more fundamental than that between mechanism and contextualism, which are just two of the many metaphors that have been employed to facilitate understanding. Regardless, it has been the major purpose of this paper to demonstrate that the case has not been made that contextualism, as defined by its current adherents, provides an approach to scientific psychology fundamentally different from that stemming from other metaphors.

\section{REFERENCES}

Adams, J. A. (1984). Learning of movement sequences. Psychological Bulletin, 96, 3-28.

Altman, I., \& RogofF, B. (1987). World views in psychology: Trait, interactional, organismic, and transactional. In B. Stokols \& I. Altman (Eds.), Handbook of environmental psychology (pp. 7-40). New York: Wiley.

BadDeley, A. D. (1982). Domains of recollection. Psychological Review, 89, 708-729.

BaLSAM, P. D. (1985). The functions of context in learning and performance. In P. D. Balsam \& A. Tomie (Eds.), Context and learning (pp. 1-22). Hillsdale, NJ: Erlbaum.
Balsam, P. D., \& Tomie, A. (Eds.) (1985). Context and learning. Hillsdale, NJ: Erlbaum.

BECHTEL, W. (1988). Philosophy of science: An overview for cognitive science. Hillsdale, NJ: Erlbaum.

BrucE, D. (1994). Lashley and the problem of serial order. American Psychologist, 49, 93-103.

Bruner, J. S., \& Minturn, A. L. (1955). Perceptual identification and perceptual organization. Journal of General Psychology, 53, 21-28.

Cicirelli, V. G. (1994). The individual in the family life cycle. In L. L'Abate (Ed.), Handbook of developmental family psychology and psychopathology (pp. 27-43). New York: Wiley.

Davies, G. M., \& Thomson, D. M. (Eds.) (1988). Memory in context: Context in memory. Chichester, U.K.: Wiley.

du Preez, P. (1991). A science of mind. San Diego, CA: Academic Press.

Evans, J. D. (1985). Invitation to psychological research. New York: Holt, Rinehart \& Winston.

FoDOR, J. A. (1974). Special sciences (or: Disunity of science as a working hypothesis). Synthese, 28, 97-115.

ForD, D. H., \& LERNER, R. M. (1992). Developmental systems theory: An integrative approach. Newburry Park, CA: Sage.

GERGEN, K. J. (1989). Social psychology and the wrong revolution. European Journal of Social Psychology, 19, 463-484.

GibBon, J., \& Balsam, P. (1981). Spreading association in time. In C. M. Locurto, H. S. Terrace, \& J. Gibbon (Eds.), Autoshaping and conditioning theory (pp. 219-253). New York: Academic Press

GILlespie, D. (1992). The mind's we: Contextualism in cognitive psychology. Carbondale: Southern Illinois University Press.

Hall, G. (1991). Perceptual and associative learning. Oxford: Oxford University Press, Clarendon Press.

Halliday, D., \& Resnick, R. (1966). Physics (Parts I and II). New York: Wiley.

Hanson, N. R. (1988). Observation. In E. D. Klemke, R. Hollinger, \& A. D. Kline (Eds.), Introductory readings in the philosophy of science (rev. ed., pp. 184-195). Buffalo, NY: Prometheus.

HAYES, S. C. (1988). Contextualism and the next wave of behavioral psychology. Behavior Analysis, 23, 7-22.

HAYES, S. C., \& HAYES, L. J. (1992). Some clinical implications of contextualistic behaviorism: The example of cognition. Behavior Therapy, 25, 223-249.

Hayes, S. C., Hayes, L. J., \& Reese, H. W. (1988). Finding the philosophical core: A review of Stephen C. Pepper's World hypotheses: A study in evidence. Journal of the Experimental Analysis of Behavior, 50, 97-111.

Hayes, S. C., Hayes, L. J., Reese, H. W., \& Sarbin, T. R. (Eds.) (1993). Varieties of scientific contextualism. Reno, NV: Context Press. Hineline, P. N. (1990). The origins of environment-based psychological theory. Journal of the Experimental Analysis of Behavior, 53, 305-320.

JeNKINS, J. J. (1979). Four points to remember: A tetrahedral model of memory experiments. In L. S. Cermak \& F. I. M. Craik (Eds.), Levels of processing in human memory (pp. 429-446). Hillsdale, NJ: Erlbaum.

KenDLER, T. S. (1986). World views and the concept of development: A reply to Lerner and Kauffman. Developmental Review, 6, 80-95.

KLATZKY, R. L. (1980). Human memory: Structure and processes (2nd ed.). San Francisco: W. H. Freeman.

KUHN, T. S. (1970). The structure of scientific revolutions (rev. ed.). Chicago: University of Chicago Press.

LASHLEY, K. S. (1951). The problem of serial order in behavior. In L. A. Jeffress (Ed.), Cerebral mechanisms in behavior: The Hixon symposium (pp. 112-136). New York: Wiley.

LERNER, R. M., \& KaUfMAN, M. B. (1985). The concept of development in contextualism. Developmental Review, 5, 309-333.

Mackintosh, N. J. (1974). The psychology of animal learning. New York: Academic Press.

MARR, M. J. (1993). Contextualistic mechanism or mechanistic contextualism?: The straw machine as tar baby. Behavior Analyst, 16, 59-65.

MediN, D. L., \& Reynolds, T. J. (1985). Cue-context interactions in discrimination, categorization, and memory. In P. D. Balsam \& 
A. Tomie (Eds.), Context and learning (pp. 323-356). Hillsdale, NJ: Erlbaum.

Meyers, L. S., \& GRossen, N. E. (1978). Behavioral research: Theory, procedure, and design (2nd ed.). San Francisco: W. H. Freeman

Morris, E. K. (1988). Contextualism: The world view of behavior analysis. Journal of Experimental Child Psychology, 46, 289-323.

MORRIs, E. K. (1991). The contextualism that is behavior analysis: An alternative to cognitive psychology. In A. Still \& A. Costall (Eds.), Against cognitivism: Alternative foundations for cognitive psychology (pp. 123-149). Hempstead, U.K.: Harvester-Wheatsheaf

Morris, E. K. (1993a). Behavior analysis and mechanism: One is not the other. Behavior Analyst, 16, 25-43.

Morris, E. K. (1993b). Contextualism, historiography, and the history of behavior analysis. In S. C. Hayes, L. J. Hayes, H. W. Reese, \& T. R. Sarbin (Eds.), Varieties of scientific contextualism (pp. 137165). Reno, NV: Context Press.

Muenzinger, K. F. (1928). Plasticity and mechanization of the problem box habit in guinea pigs. Journal of Comparative Psychology, $8,45-69$.

MUenzinger, K. F., Koerner, L., \& Irey, E. (1929). Variability of an habitual movement in guinea pigs. Journal of Comparative Psychology, 9, 425-436.

Pepper, S. C. (1942). World hypotheses: A study in evidence. Berkeley: University of California Press.

PePPer, S. C. (1967). Concept and quality. La Salle, IL: Open Court.

PoPPER, K. R. (1970). Normal science and its dangers. In I. Lakatos \& A. Musgrave (Eds.), Criticism and the growth of knowledge (pp. 5158). New York: Cambridge University Press.

Postman, L. (1972). A pragmatic view of organization theory. In E. Tulving \& W. Donaldson (Eds.), Organization of memory (pp. 348). New York: Academic Press.
REESE, H. W. (1991). Contextualism in developmental psychology. In H. W. Reese (Ed.), Advances in child development and behavior (pp. 187-230). Orlando, FL: Academic Press.

Rescorla, R. A., Durlach, P. J., \& Grau, J. W. (1985). Contextual learning in Pavlovian conditioning. In P. D. Balsam \& A. Tomie (Eds.), Context and learning (pp. 23-56). Hillsdale, NJ: Erlbaum. Rosnow, R. L., \& Georgoudi, M. (Eds.) (1986). Contextualism and understanding in behavioral science. New York: Praeger.

SARBIN, T. R. (1993). The narrative as the root metaphor for contextualism. In S. C. Hayes, L. J. Hayes, H. W. Reese, \& T. R. Sarbin (Eds.), Varieties of scientific contextualism (pp. 51-65). Reno, NV: Context Press.

SPEAR, N. E., \& Riccio, D. C. (1994). Memory: Phenomena and principles. Boston: Allyn \& Bacon.

SPENCE, K. W. (1956). Behavior theory and conditioning. New Haven, CT: Yale University Press.

Staddon, J. E. R. (1993). Pepper with a pinch of psalt. Behavior Analyst, 16, 245-250.

Swartzentruber, D., \& Bouton, M. E. (1992). Context sensitivity of conditioned suppression following preexposure to the conditioned stimulus. Animal Learning \& Behavior, 20, 97-103.

TERWEE, J. S. (1990). Hermeneutics in psychology and psychoanalysis. New York: Springer-Verlag.

Tolman, E. C. (1932). Purposive behavior in animals and men. New York: Appleton-Century-Crofts.

WARREN, R. M. (1970). Perceptual restorations of missing speech sounds. Science, 167, 392-393.

(Manuscript received December 21, 1993; revision accepted for publication February 14, 1994.) 